\title{
L-band scintillation and TEC variations on St. Patrick's Day storm of 17 March 2015 over Indian longitudes using GPS and GLONASS observations
}

\author{
V K D Srinivasu ${ }^{1, *} *_{\odot}$, D S V V D Prasad ${ }^{1}, \mathrm{~K} \mathrm{Niranjan}^{1}$, \\ Gopi K Seemala ${ }^{2}$ and K Venkatesh ${ }^{3}$ \\ ${ }^{1}$ Department of Physics, Andhra University, Visakhapatnam 530 003, India. \\ ${ }^{2}$ Indian Institute of Geomagnetism, Panvel, Navi Mumbai 410 218, India. \\ ${ }^{3}$ National Atmospheric Research Laboratory (NARL), Gadanki 517 112, India. \\ *Corresponding author.e-mail: vkdsrinivasu@gmail.com
}

MS received 1 March 2018; revised 12 July 2018; accepted 16 July 2018; published online 11 March 2019

The aim of the present study is to investigate the response of ionospheric total electron content (TEC), Global Positioning System (GPS) and Global Navigation Satellite System (GLONASS) scintillations during 17 March 2015 St. Patrick's Day geomagnetic storm over Visakhapatnam, which is popularly known as Waltair (WALT) in the literature. GPS TEC observations obtained from five IGS stations (SGOC, IISC, HYDE, LCK4 and LHAZ) and WALT during the storm have been compared. The TEC derived from GPS, GLONASS constellations and CODE global ionosphere TEC map (GIM) over WALT has also been compared. Positive storm effect during the main phase of the storm and negative storm effect during the recovery phase of the storm were observed over the said stations. The variation of northern equatorial ionisation anomaly TEC (CODE GIM TEC maps) in response to the St. Patrick's Day storm over four Indian longitudes $\left(75^{\circ} \mathrm{E}, 80^{\circ} \mathrm{E}, 85^{\circ} \mathrm{E}\right.$ and $\left.90^{\circ} \mathrm{E}\right)$ has also been presented. Strong amplitude and phase scintillations were observed in the L-band signals of GPS and GLONASS constellations over WALT. Twelve satellite (Pseudo Random Noise) PRNs of GPS L1 and nine PRNs of each GLONASS L1 and L2-band signals were affected by strong amplitude and phase scintillation. The peak amplitude scintillation index (S4) obtained from the effected PRNs of GPS L1 signal and GLONASS L1-band signals over WALT range from 0.36 to 0.74 and 0.36 to 0.76 , respectively. Strong fluctuations in rate of TEC index are noted over the said stations. This enhanced scintillation activity is mainly due to the main phase of the storm falls in the evening sector over the Indian region.

Keywords. Magnetic storm; L-band scintillations; GPS; GLONASS; ROTI.

\section{Introduction}

Severe space weather induces perturbations in the composition, dynamics and geomagnetic field of the Earth's upper atmosphere, which sometimes causes serious threats to the global navigation and satellite communication systems. The geomagnetic disturbance of ionosphere induced by the interaction of solar wind energy with magnetosphere-ionosphere-thermosphere system is popularly known as ionospheric storm (e.g., literature reviews by Gonzalez et al. 1994; Prölss 1995; Abdu 1997; Loewe and Prölss 1997; Forster and Jakowski 2000; Danilov 2013). During the 
storm, the neutral and electrodynamical processes couple the high- and low-latitude ionospherethermosphere system, which lead to severe modifications in the electric fields of equatorial and low-latitude ionosphere (Nishida 1968; Blanc and Richmond 1980; Kikuchi et al. 2000). As a result, the global scale equatorial zonal electric field was severely perturbed and would cause disturbances in the ionosphere electrodynamics. During the storm, dusk side strong perturbations in the electron density of the ionosphere and their related electrodynamics severely disturb the transionosphere radio wave propagation. The occurrence of disturbances in ionosphere is distinct and complex for each individual storm and affects the radio wave communication, which has gained much importance in the present research scenario.

Storm time perturbations are mainly caused by two dynamic electric field processes, namely prompt penetration electric field (PPEF) and disturbance dynamo electric field (DDEF). The former is due to the penetration of the high-latitude electric field with global scale equatorial electric field (Nishida 1968). The relative polarities and magnitudes of R1 and R2 currents can cause fieldaligned convection currents, i.e., associated electric fields (under shielding/over shielding) fed into the global scale zonal electric field. The R2 field-aligned currents during southward IMF $\mathrm{Bz}$ period, and their associated convection electric fields, penetrate into the global scale electric fields in the equatorial latitudes, which result in PPEF (Nishida 1968; Kikuchi et al. 1996, 2000). PPEF will be generated simultaneously with the changes in IMF Bz and lasts for a few minutes $(\sim 30-120 \mathrm{~min})$. This short-lived PPEF can couple with the global scale equatorial zonal electric field and cause enhancement (suppression) in the net electric field. Hence, the consequent electrodynamics lifts the ionosphere plasma upward (downward) where ion recombination rate is very less (high). This will enhance (low) plasma at higher (lower) altitudes, resulting in the modification of diurnal variation of the plasma density. The plasma density is higher (lower) than the quiet time values, which can cause positive (negative) storm effect (Prölss 1995; Fuller-Rowell et al. 1996). The onset of the sub-storm may also induce eastward electric field in the dayside of equatorial ionosphere when the IMF $\mathrm{Bz}$ is in a southward direction (Huang 2009, 2012).

DDEFs will be generated by the deposition of solar wind energy into the high-latitude thermosphere, and consequent Joule heating can cause disturbance dynamo in electric fields via global scale thermosphere wind circulation (Blanc and Richmond 1980). These DDEFs will be generated few hours after the storm commencement and last for several hours to several days (Scherliess and Fejer 1997; Richmond et al. 2003). Disturbance dynamo induces downward (upward) drifts on the dayside and suppresses (enhances) the equatorial ionisation anomaly (EIA) (Scherliess and Fejer 1997). PPEFs, DDEFs and their superposition on equatorial electric fields can cause complex variability in the vertical plasma drifts of the ionosphere (Sastri et al. 2003; Tulasi Ram et al. 2008). In addition to above fields, the increased (decreased) $\mathrm{O} / \mathrm{N}_{2}$ ratio, storm-time thermosphere winds and plasma sphere downward fluxes manifest the occurrence of positive (negative) storm effect (Rishbeth 1991; Prölss 1995; Fuller-Rowell et al. 1996).

It is well known that the neutral and electrodynamic interactions induced by the storms on the ionosphere-thermosphere vary with latitude, altitude, local time, season and phase of the solar activity. If the main phase of the storm falls during dusk-to-dawn sector, then the storm-induced perturbation equatorial electric fields in addition to pre-reversal enhancements (PRE) would be responsible for the altitudinal uplift/suppression of plasma in the equatorial ionosphere. This leads to the development/inhibition of post-sunset equatorial spread-F (ESF) irregularities (Blanc and Richmond 1980; Yeh and Lui 1982; Abdu 1997; Fejer et al. 1999; Kikuchi et al. 2000; Huang et al. 2001) through generalised Rayleigh-Taylor instability mechanism. Fejer et al. (2008) have investigated the seasonal dependence of longitudinally averaged equatorial PPEF and disturbance dynamo vertical drifts, and found that the prompt penetration drifts are mostly upward/downward during night-time/daytime in all seasons, respectively. Many researchers have been studying the scintillations on Global Positioning System (GPS) L-band signals during quiet and disturbed periods over Indian sector (Tulasi Ram et al. 2008, 2015; Ramsingh Sripathi et al. 2015; Srinivasu et al. 2017).

On St. Patrick's Day of 17 March 2015, a distinct class of two-step storm was formed by the superposition of two moderate storms (Kamide and Kusano 2015), which is a distinct type of geomagnetic storm during the 24th solar cycle so far. Many studies have been conducted on this storm over various sectors around the globe and observed 
distinct features in electron density, $\mathrm{O} / \mathrm{N}_{2}$, F-layer parameters, total electron content (TEC), global total electron content (GEC) and regional total electron content (REC) by using various ground and satellite-based instruments (Astafyeva et al. 2015; Ramsingh Sripathi et al. 2015; Tulasi Ram et al. 2015; Borries et al. 2016; Fagundes et al. 2016; Huang et al. 2016; Kalita et al. 2016; Kuai et al. 2016; Nava et al. 2016; Patra et al. 2016; Zakharenkova et al. 2016; Nayak et al. 2017; Venkatesh et al. 2017). Astafyeva et al. (2015) have reported the occurrence of positive storm, negative storm and hemispherical asymmetry over Eastern Pacific, European, African and American sectors. Borries et al. (2016) have reported perturbations in TEC and wavelike characteristics of large-scale travelling ionosphere disturbances propagating towards equator over African-European sector. Fagundes et al. (2016) have shown anomalous behaviour of EIA caused by wavelike structures during the main phase of the storm and the suppression of EIA (negative storm effect) during the recovery phase of the storm over east and west Brazilian sectors. Venkatesh et al. (2017) have reported the rapid uplift of F2 layer peak, redistribution of plasma into F2 and F3 layers and their consequent signatures on TEC and EIA over Brazilian sector including the stormtime hemispheric asymmetry. Carter et al. (2016) have demonstrated the equatorial plasma bubbles (EPBs) using coupled thermosphere-ionosphere model and the influence of DDEF on the equatorial ionosphere after the storm commencement and the resulted suppression and growth of the post-sunset and post-midnight EPBs. Zakharenkova et al. (2016) have investigated the travelling ionospheric disturbances (TIDs) from GPS and GLONASS observations, particularly over Europe and American sectors.

Over Indian sector, Ramsingh Sripathi et al. (2015) and Tulasi Ram et al. (2015) have reported that the h'F over Tirunelveli (equatorial station) was lifted to $\sim 560 \mathrm{~km}$ with a vertical drift of $70 \mathrm{~m} / \mathrm{s}$. Patra et al. (2016) have observed the uplift of the $\mathrm{F}$ layer to $\sim 470 \mathrm{~km}$ with a peak upward velocity $50 \mathrm{~m} / \mathrm{s}$ over Gadanki (off-equatorial station), subsequent generation of post-sunset ESF irregularities and GPS L-band scintillations. Patra et al. (2016) have reported that the observed EPBs and irregularities were confined to a narrow longitudinal zone extending from $69^{\circ}-98^{\circ} \mathrm{E}$, which is due to the reversal of the zonal drift of the irregularities from eastward to westward within a short span ( $\sim 30 \mathrm{~min})$ at around 21:45 IST. Tulasi Ram et al. (2015) have found that an uplift of plasma over a narrow longitudinal sector on sunset terminator, which has an extension of EPBs between $27.13^{\circ} \mathrm{N}$ and $25.98^{\circ} \mathrm{S}$ magnetic dip latitudes at an apex altitude of $\sim 1670 \mathrm{~km}$. From these studies, it is clear that if the main phase of the storm falls on dusk-to-dawn sector, then it is more favourable for the generation of electron density irregularities. An attempt is made in this study to understand the irregularity signatures and their strengths on L-band signals of GPS, GLONASS constellations along with the TEC variations over Waltair (WALT) during 17 March 2015. To support and know the global ionosphere TEC map (GIM) TEC response over Indian sector, we considered time series GIM data over four closely spaced (with $5^{\circ}$ difference) longitudes during 16-19 March 2015. To study the scintillation signatures on GPS TEC in terms of rate of TEC index (ROTI) during dusk-to-dawn sector on 17 March 2015, we have considered five IGS stations over the said Indian longitudes and discussed the salient features and their probable physical mechanisms.

\section{Data and methodology}

Ionospheric vertical TEC derived from GPS and GLONASS constellations over WALT during 1619 March 2015 was considered. The Rinex data

Table 1. List of stations and their coordinates.

\begin{tabular}{|c|c|c|c|c|c|c|}
\hline $\begin{array}{l}\text { Sl. } \\
\text { no. }\end{array}$ & Station and country & Code & Network & Latitude & Longitude & $\begin{array}{c}\text { Geomagnetic } \\
\text { latitude }\end{array}$ \\
\hline 1 & Narahenpita, Sri Lanka & SGOC & IGS & $6.89^{\circ} \mathrm{N}$ & $79.87^{\circ} \mathrm{E}$ & $1.76^{\circ} \mathrm{S}$ \\
\hline 2 & Bangalore, India & IISC & IGS & $13.02^{\circ} \mathrm{N}$ & $77.57^{\circ} \mathrm{E}$ & $4.49^{\circ} \mathrm{N}$ \\
\hline 3 & Waltair, India & WALT & GPStation 6 & $17.73^{\circ} \mathrm{N}$ & $83.32^{\circ} \mathrm{E}$ & $8.71^{\circ} \mathrm{N}$ \\
\hline 4 & Hyderabad, India & HYDE & IGS & $17.41^{\circ} \mathrm{N}$ & $78.55^{\circ} \mathrm{E}$ & $8.77^{\circ} \mathrm{N}$ \\
\hline 5 & Lucknow, India & LCK4 & IGS & $26.91^{\circ} \mathrm{N}$ & $80.95^{\circ} \mathrm{E}$ & $18.01^{\circ} \mathrm{N}$ \\
\hline 6 & Lhasa, China & LHAZ & IGS & $29.65^{\circ} \mathrm{N}$ & $91.10^{\circ} \mathrm{E}$ & $20.16^{\circ} \mathrm{N}$ \\
\hline
\end{tabular}




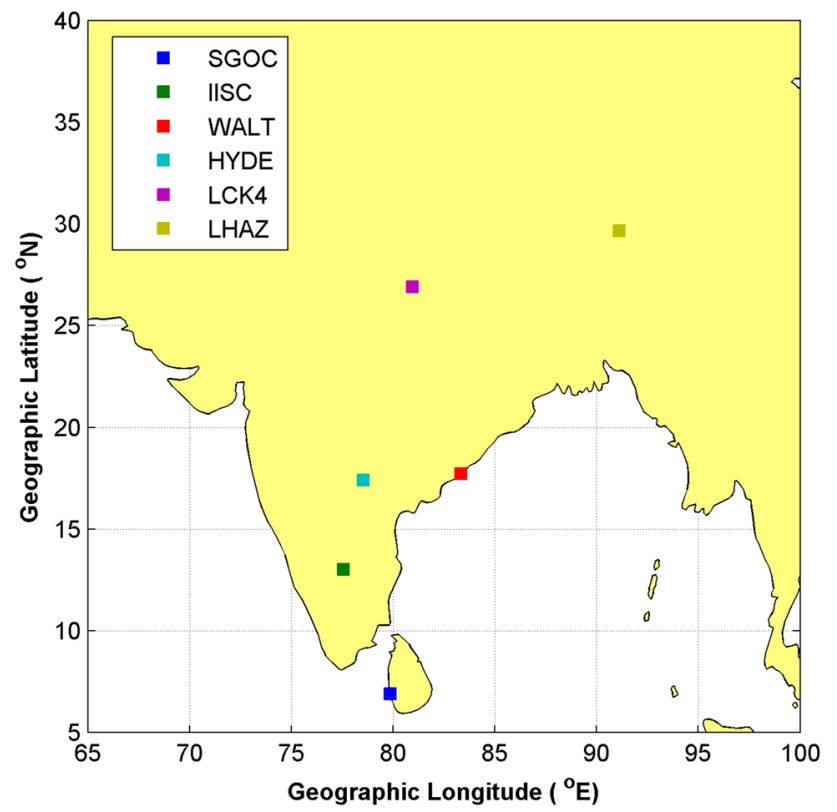

Figure 1. Geographic locations and their station codes of five IGS and GPStation-6 receiver.

files obtained at five IGS stations listed in table 1 during the storm period are used. The geographic locations of the stations listed in table 1 are shown in figure 1. The Rinex data files were processed and GPS TEC values are computed according to Seemala and Valladares (2011) and ROTI according to $\mathrm{Pi}$ et al. (1997). TEC observations with an elevation $>50^{\circ}$ (Rama Rao et al. 2006) are only considered. To observe the TEC trend over Indian longitudes, CODE GIM data have been taken from the web page ftp://cddis.gsfc.nasa. gov/pub/gps/products/ionex. The 2 hourly GIM data files are processed by using $\mathrm{C}$ programming and interpolation (temporal as well as spatial) is adopted to obtain a continuous time series of hourly vertical total electron content (VTEC) for every latitude and longitude with an interval of $2.5^{\circ}$ (lat.) and $5^{\circ}$ (lon.), respectively. We extracted the time series TEC data from a CODE GIM TEC over four longitudes $75^{\circ} \mathrm{E}, 80^{\circ} \mathrm{E}, 85^{\circ} \mathrm{E}$, and $90^{\circ} \mathrm{E}$ during storm periods. GIM CODE TEC at WALT was computed by taking mean TEC over a grid of $2.5^{\circ} \times 5^{\circ}$ (lat. $\times$ lon.) around WALT. To get a rough idea of PPEFs over the said longitudes during the storm period, we have considered model-derived prompt penetration equatorial electric fields (PPEFs). These PPEFs were taken from http://geomag.org/models/PPEFM/ RealtimeEF.html (Manoj and Maus 2012). The amplitude and phase scintillation data (respectively, per minute $\mathrm{S} 4$ and $60 \mathrm{~s}$ phase sigma) on 17 March 2015 over WALT obtained from Novatel ISM REDOBS logs were used in this study. These NovAtel ISM REDOBS logs are derived from raw data using PARSEREDUCED utility, and they do not include GPS L2 scintillation measurements (GPStation-6TM 2012). To compare the storm time observations with quiet day observations, five magnetically quiet days were taken from the World Data Centre (WDC) for Geomagnetism, Kyoto (http://wdc.kugi.kyoto-u. ac.jp/qddays/index.html). The storm time parameters of per minute interplanetary solar wind speed (SW), IMF Bz, auroral electro jet indices (AE, AU and $\mathrm{AL}$ ) and SYM-H and 3-h KP index were taken from the OMNI Web interface (https://omniweb. gsfc.nasa.gov/form/omni_min.html).

\section{Results and discussions}

\subsection{St. Patrick's Day storm morphology}

Coronal mass ejection associated with solar flare C9.1 originated from sunspot AR2297 hit the Earth's magnetosphere at 04:45 UT on 17 March 2015. As a result, sudden enhancement occurred in an interplanetary magnetic field component (IMF $\mathrm{Bz}$ ), turned northward and started a sudden storm commencement (SSC), which was a great geomagnetic storm during solar cycle 24. Figure 2 shows the variation of SYM-H, solar wind parameters (SW velocity, SW density), auroral electro-jet indices (AE, AU and $\mathrm{AL}$ ) and $\mathrm{Kp}$ index during 16-19 March 2015. After the SSC, a large enhancement was observed in the solar wind parameters (wind speed and density) and symmetrical ring current index (SYM-H). Enhancement was noted in auroral electro jet indices (AE and $\mathrm{AL}$ ) after the SSC with some time delay, which is shown in figure 2. Northward-turned IMF $\mathrm{Bz}$ reached to $\sim 25 \mathrm{nT}$ after $\mathrm{SSC}$, and SYM-H raised to $\sim 67 \mathrm{nT}$ and solar wind speed reached to $\sim 550 \mathrm{~km} / \mathrm{s}$. On 17 March 2015, at 07:00 UT by the turning of IMF Bz towards the south, the onset of the main phase of the storm was started. During the main phase, the solar wind speed, Kp index and the AE index rose to a maximum of $\sim 600 \mathrm{~km} / \mathrm{s}, 8$ and $\sim 2300 \mathrm{nT}$, respectively. Complex behaviour in the orientation of IMF $\mathrm{Bz}$ and large fluctuations in auroral electro jet indices were noted during this phase. The main phase of the storm was lasted for about $\sim 18 \mathrm{~h}$. During this period, IMF Bz turned southward at 07:00 UT, and after 


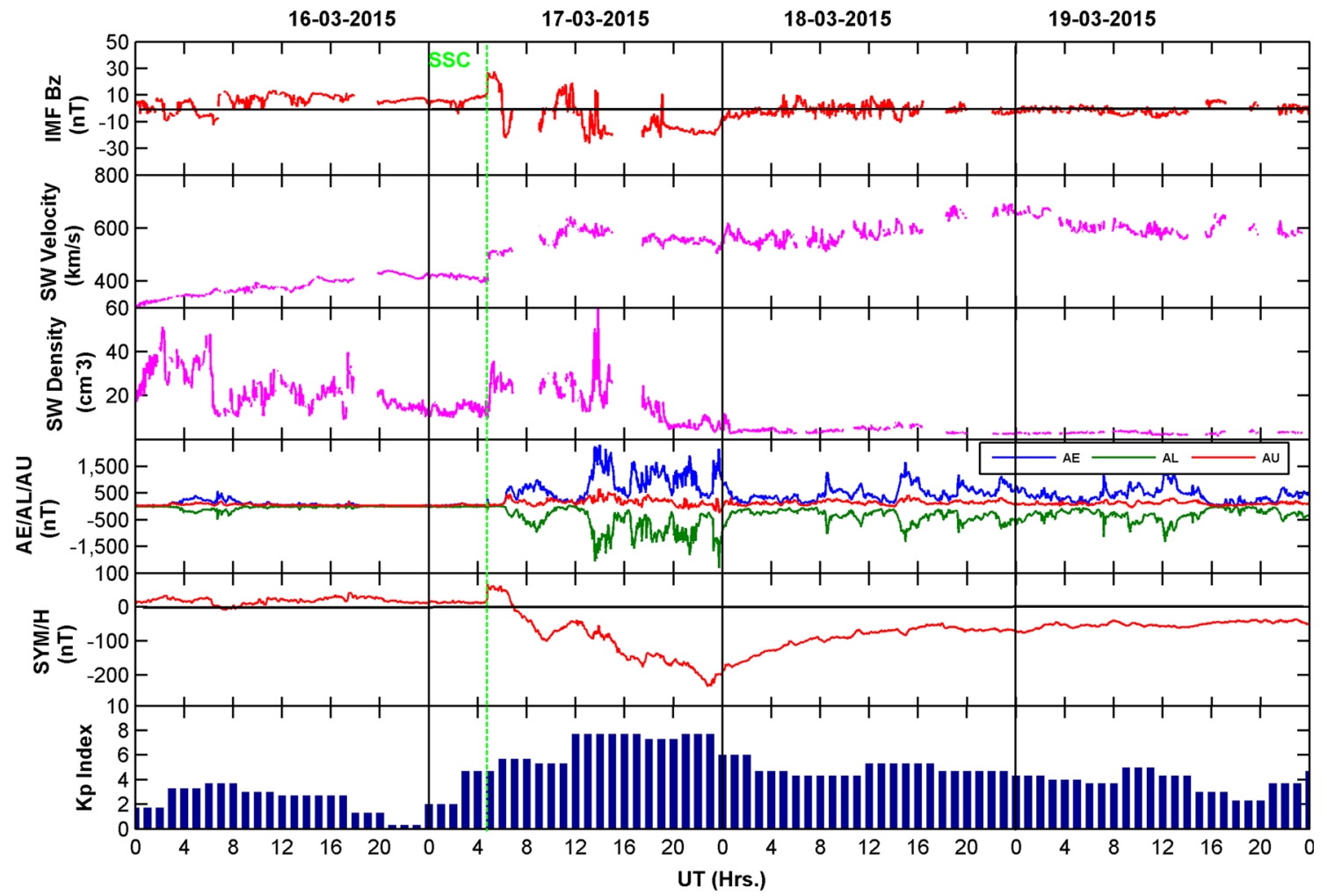

Figure 2. Temporal variations of IMF Bz, solar wind speed, solar wind density, auroral electro jet indices (AE, ASU and AL), SYM-H and Kp index during 16-19 March 2015.

suffering few north-south fluctuations, it again turned southward at $\sim 12: 30$ UT. Consequently, the symmetric ring current (SYM-H) decreased to $-100 \mathrm{nT}$ at $\sim 09: 30 \mathrm{UT}$, and after a brief recovery, SYM-H rose to a minimum value of $-232 \mathrm{nT}$ at around 23:04 UT. Kamide and Kusano (2015) have observed that this storm has occurred without any precursory X- or M-type solar flares, and this was a distinct class of two-step storm formed by the superposition of two successive moderate storms driven by two southward IMF Bz turnings. Recovery of SYM-H had started at 23:05 UT on 17 March 2015 and continued for a few days to reach a quiet time value. During this recovery phase, the solar wind speed remained higher at $\sim 550 \mathrm{~km} / \mathrm{s}$ and the same continued until 26 March (up to 19 March only shown in figure 2).

\subsection{Response of TEC during St. Patrick's Day storm}

It is very important to study the TEC response during the storm from various constellations, which can increase the spatial coverage in assuming volume over a station. Figure 3 represents the variation of diffTEC (Disturbed day TEC-5 Quite days mean TEC) from GPS and GLONASS constellations and GIM during 16-19 March 2015 over WALT. In figure 3, red, magenta and green colours represent the diffTEC of GPS, GLONASS and GIM, respectively. It is observed that the GLONASS diffTEC remained higher than that of GPS about $\sim 4$ TECU during the period. From figure 3 on 17 March 2015 during the 08:00 to 12:30 UT, all the systems (GPS, GLONASS and GIM CODE) showed positive storm effect, which was consistent with earlier reports over Indian sector. At around $\sim 12: 30 \mathrm{UT}$, a sharp downfall of diffTEC was seen in all the systems, and at the same time, diffTEC became negative and resulted in a negative storm effect. This negative storm phase had continued till 23:00 UT on 17 March 2015. During this period, it was observed that the negative storm effect was larger in diffTEC of GPS and GLONASS (a depression of 30 TECU) when compared to that of GIM (a depression of $\sim 10$ TECU). Positive and negative storm effects observed over WALT during the main phase of the storm are well consistent with the previous reports on this storm by Ramsingh Sripathi et al. (2015) and Tulasi Ram et al. (2015) over Indian sector. Some jumps were observed on the GLONASS 


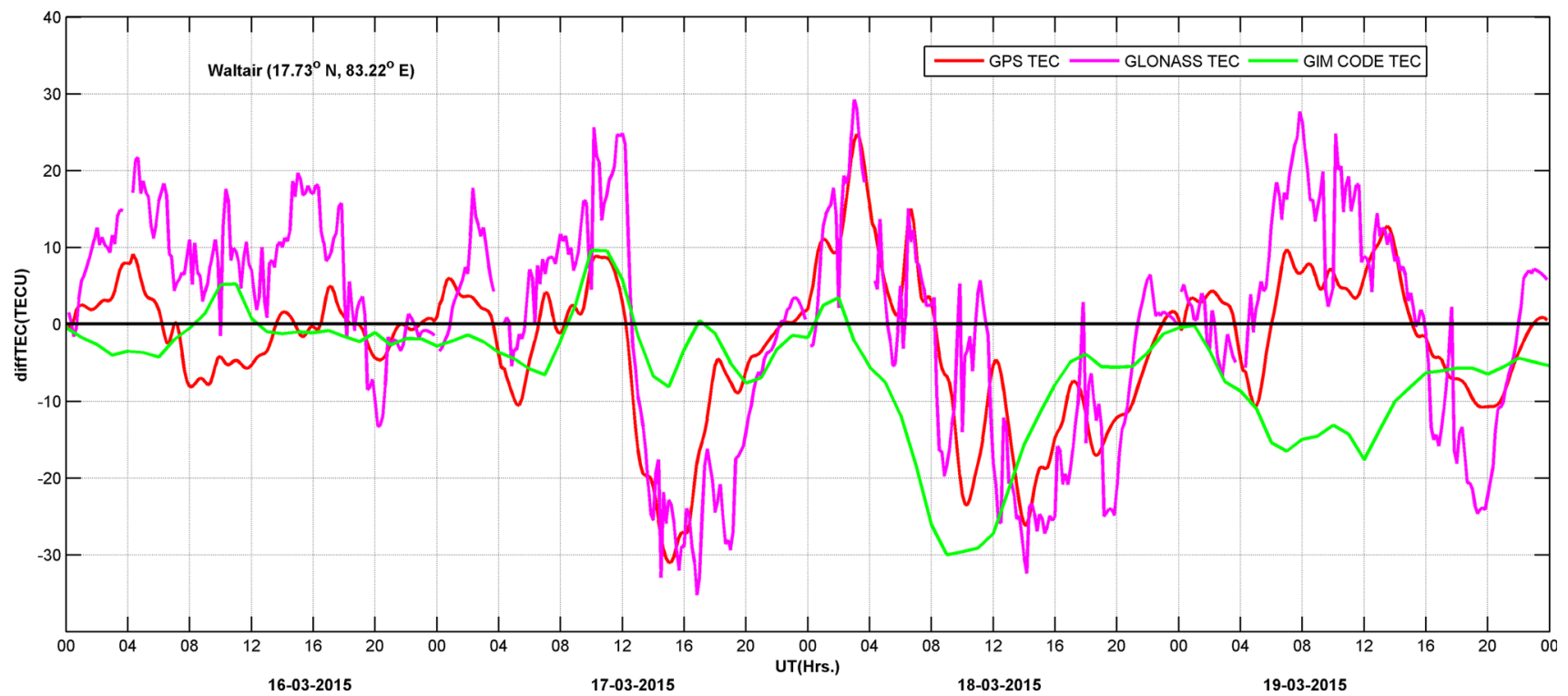

Figure 3. diffTEC (disturbed day-quiet day mean TEC) from GPS (red), GLONASS (magenta) and GIM (green) over WALT (top panel) and Vaddeswaram (bottom panel) during 16-19 March 2015.

diffTEC curve, which are due to the lesser temporal coverage of GLONASS satellites compared to GPS over WALT. The spatial (in the sense visibility of satellites over a particular time epoch) and temporal coverage of GPS constellation are better than that of the GLONASS constellation over WALT (Srinivasu et al. 2017).

During the recovery phase of the storm on 18 March 2015, except for GIM, positive storm effect was observed in GPS and GLONASS between 0000 and 06:00 UT. Three peak structures of positive storm effect were observed in GPS and GLONASS on 18 March 2015. A depression in TEC was seen with GPS and GLONASS at 14:00 UT on 18 March 2015; this may be due to north-south fluctuations of IMF $\mathrm{Bz}$ and rise in AE. A positive storm effect during 0000 to $~ 02: 30$ UT and a strong negative storm effect during $\sim 02: 00$ to $\sim 23: 55$ UT on 18 March were observed in GIM diffTEC. During the recovery phase of the storm, on 19 March 2015, the GIM diffTEC showed a negative storm effect and was anti-correlated with that of GPS and GLONASS. Generally, the CODE GIM TEC data are modelled in a solar-geomagnetic reference frame using a spherical harmonic expansion from GPS/GLONASS-combined data sets from IGS stations by adopting an interpolation technique. The WALT station is in the ionisation anomaly region. Over the Indian region, during this storm, the GPS/GLONASS-combined data sets from the IGS stations HYDE, IISC and LHAZ are only used for generating the GIM TEC, which may be one of the causes for the underestimation of the TEC. AE index had risen to a value of $12: 30$ UT on 18 March around 09:00 UT, and thereafter, DDEFs strongly influenced the ionosphere electrodynamics, and hence, $\mathrm{O} / \mathrm{N}_{2}$ ratio decreased (Astafyeva et al. 2015; Huang et al. 2016; Nava et al. 2016). As a result, a large suppression of the ionisation was observed over mid-latitudes compared to lowlatitudes (Astafyeva et al. 2015).

To get a rough idea on perturbing electric fields during the main phase of the storm, model-derived PPEFs (Manoj and Maus 2012; Kakad et al. 2016; Nayak et al. 2017) over Indian longitudes were presented in figure 4 . Figure 4 shows the variation of PPEFs over $75^{\circ}, 80^{\circ}, 85^{\circ}$ and $90^{\circ} \mathrm{E}$ longitudes (top to bottom panels, respectively). The blue curve represents background quiet time electric field, whereas the red curve represents the total electric field (PPEFs are superimposed on quiet time electric fields). On 17 March, wavelike structure, two large peaks centred at $\sim 06: 00$ and $\sim 13: 00$ UT were observed in PPEFs over the said longitudes. Generally, PPEFs will be generated simultaneously with the SSC and has coupled with the zonal eastward electric fields. This may be seen over the abovesaid longitudes in figure 4 during this storm. The observed fields can enhance the upward vertical drifts, and a consequent enhancement in the electron density will be observed over an EIA region on the dayside.

To study the variation of GPS TEC over the five IGS stations (table 1) over Indian longitudes 


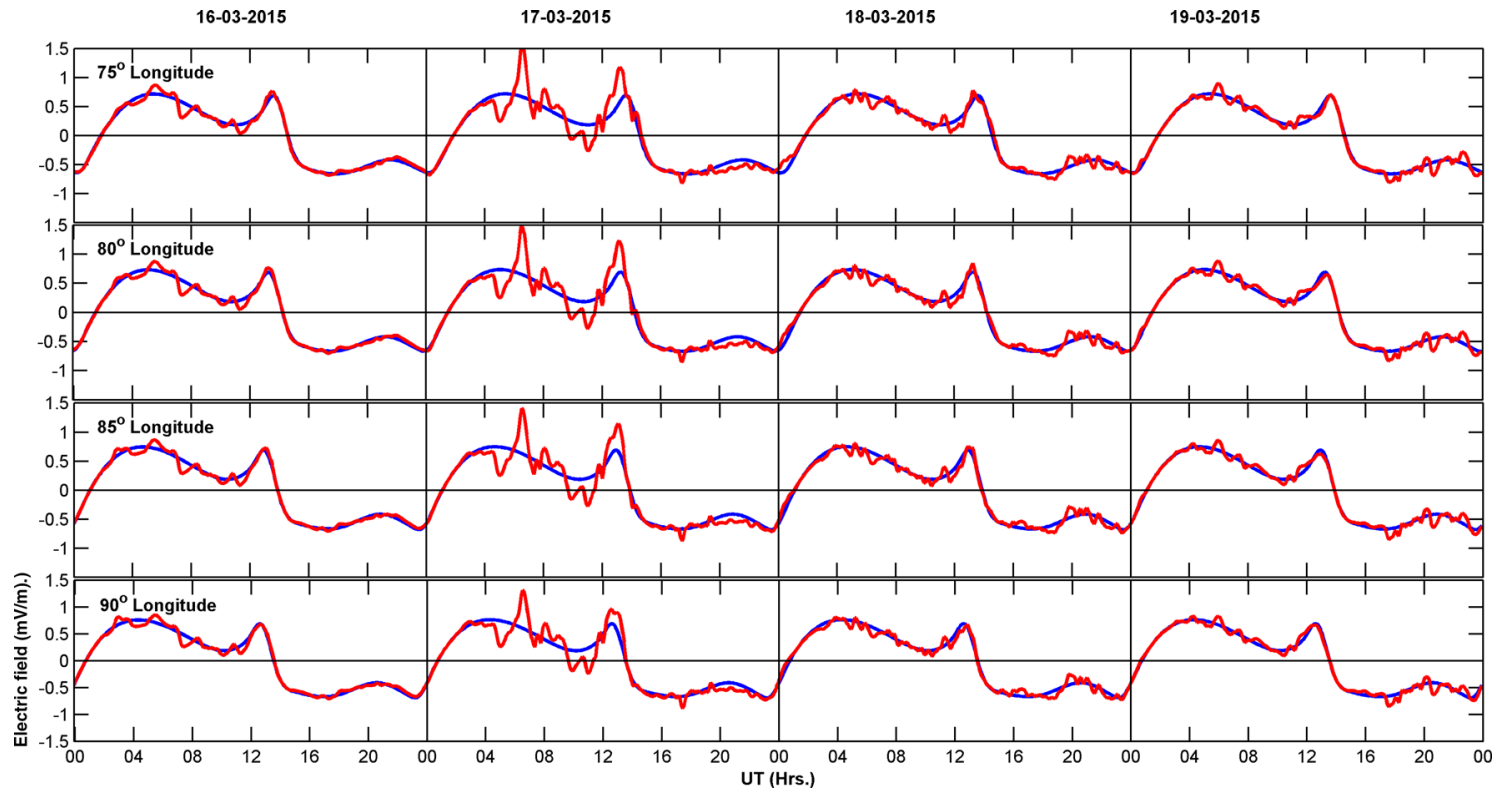

Figure 4. Variation of model-derived prompt penetration electric field (red) and quiet time electric filed (blue) during 16-19 March 2015 over $75^{\circ} \mathrm{E}, 80^{\circ} \mathrm{E}, 85^{\circ} \mathrm{E}$ and $90^{\circ} \mathrm{E}$ longitudes.

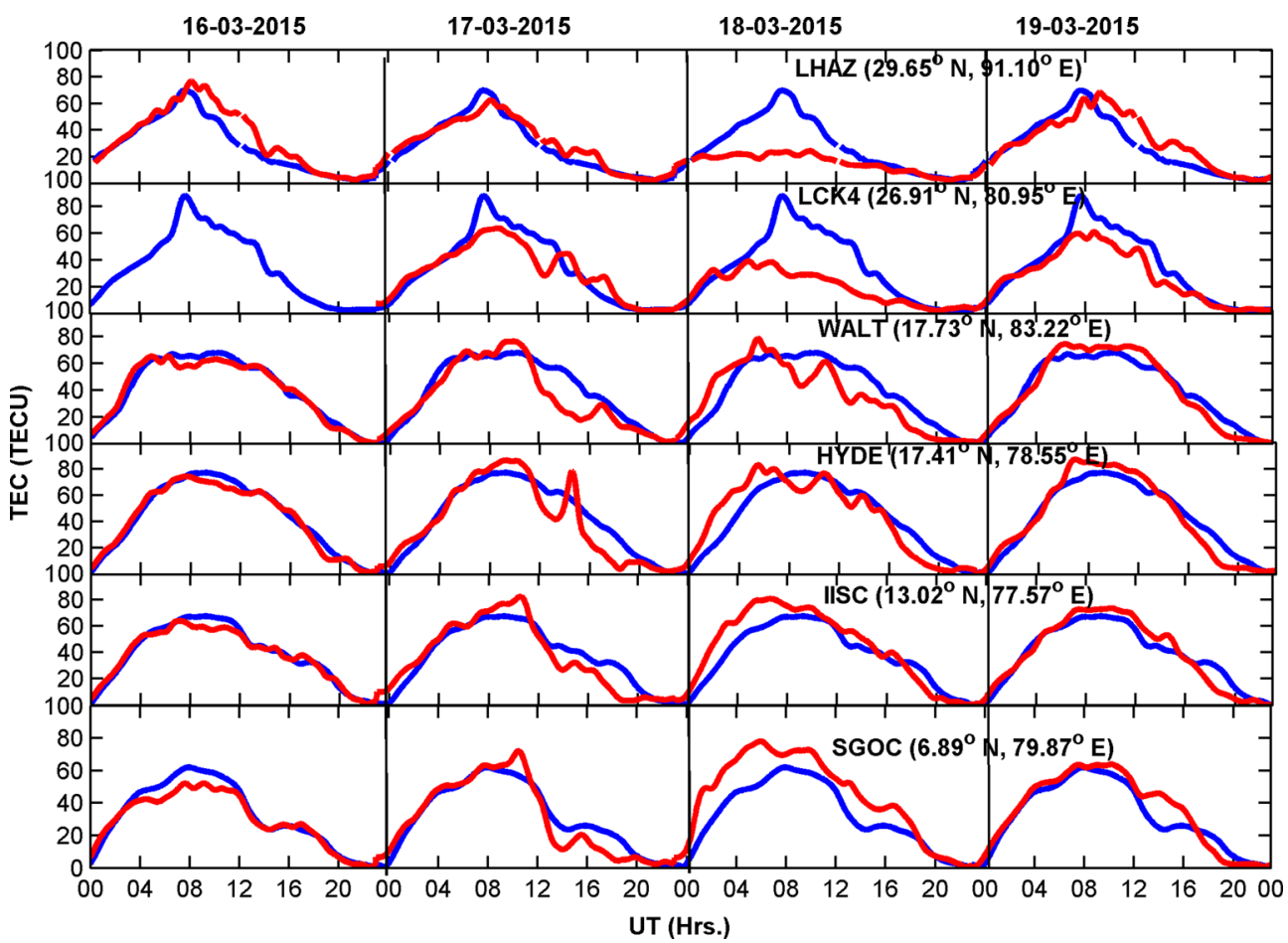

Figure 5. Diurnal variation of GPS TEC (blue: quiet time TEC, red: storm time TEC) during 16-19 March 2015.

along with WALT, we analysed the GPS TEC data and the results were presented in figure 5 . We also considered model-derived CODE GIMs to know the variation of TEC over Indian longitudes and are presented in figures 6 and 7 . Figure 5 represents the GPS TEC variation over the stations listed in table 1 . The blue curve represents mean TEC of five geomagnetic quiet days and red curve represents the TEC during the storm. Each panel of figure 5 from bottom to top was arranged in the latitudinal order. Figures 6 and 7 show the variation of GIMs and diffTEC GIMs (difference of GIM TEC with respect to quiet time mean GIM TEC) over Indian longitudes $75^{\circ} \mathrm{E}, 80^{\circ} \mathrm{E}, 85^{\circ} \mathrm{E}$ and $90^{\circ} \mathrm{E}$, respectively, for the period of $16-19$ March 2015. 


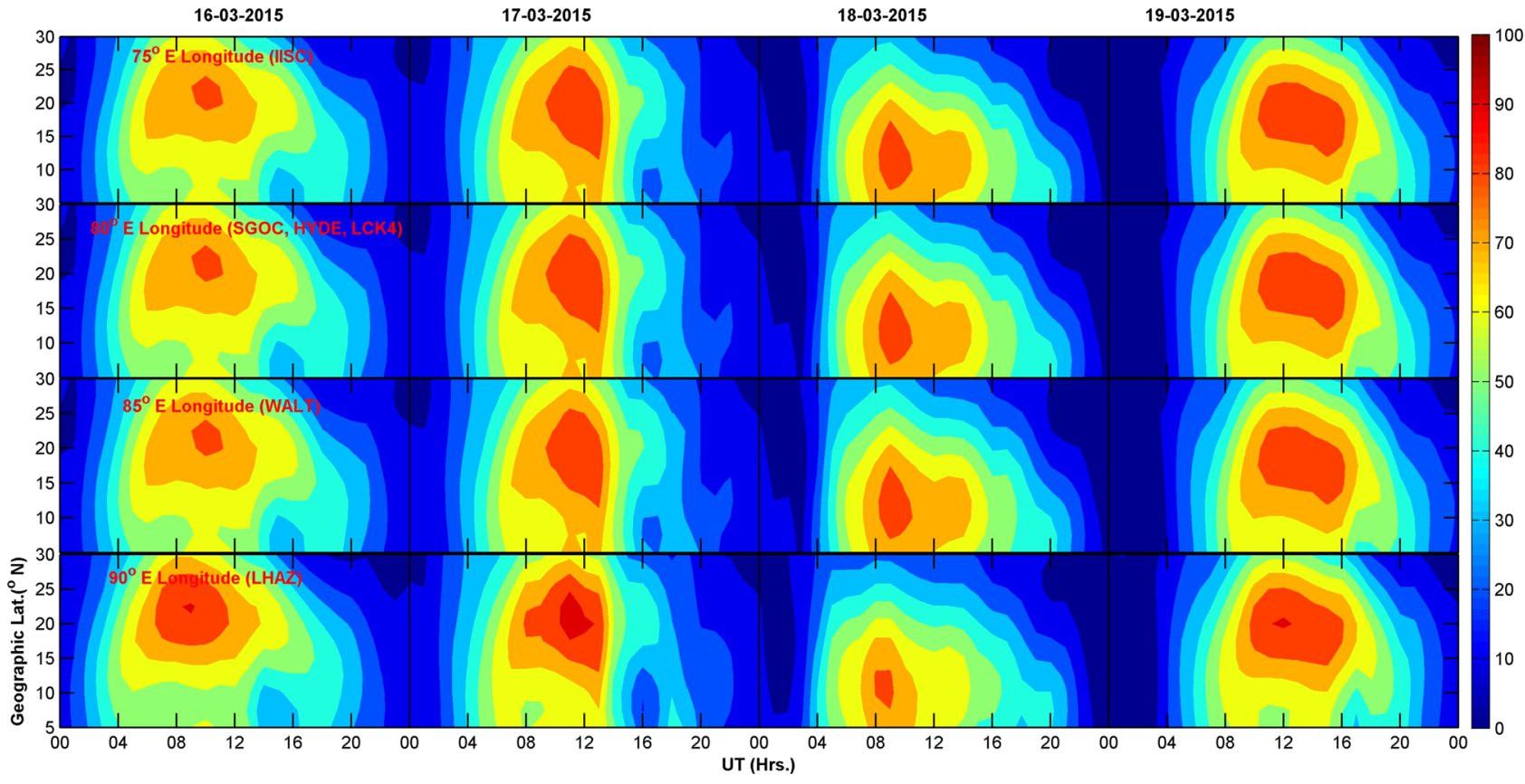

Figure 6. GIM TEC maps over $75^{\circ} \mathrm{E}, 80^{\circ} \mathrm{E}, 85^{\circ} \mathrm{E}$ and $90^{\circ} \mathrm{E}$ longitudes during 16-19 March 2015.

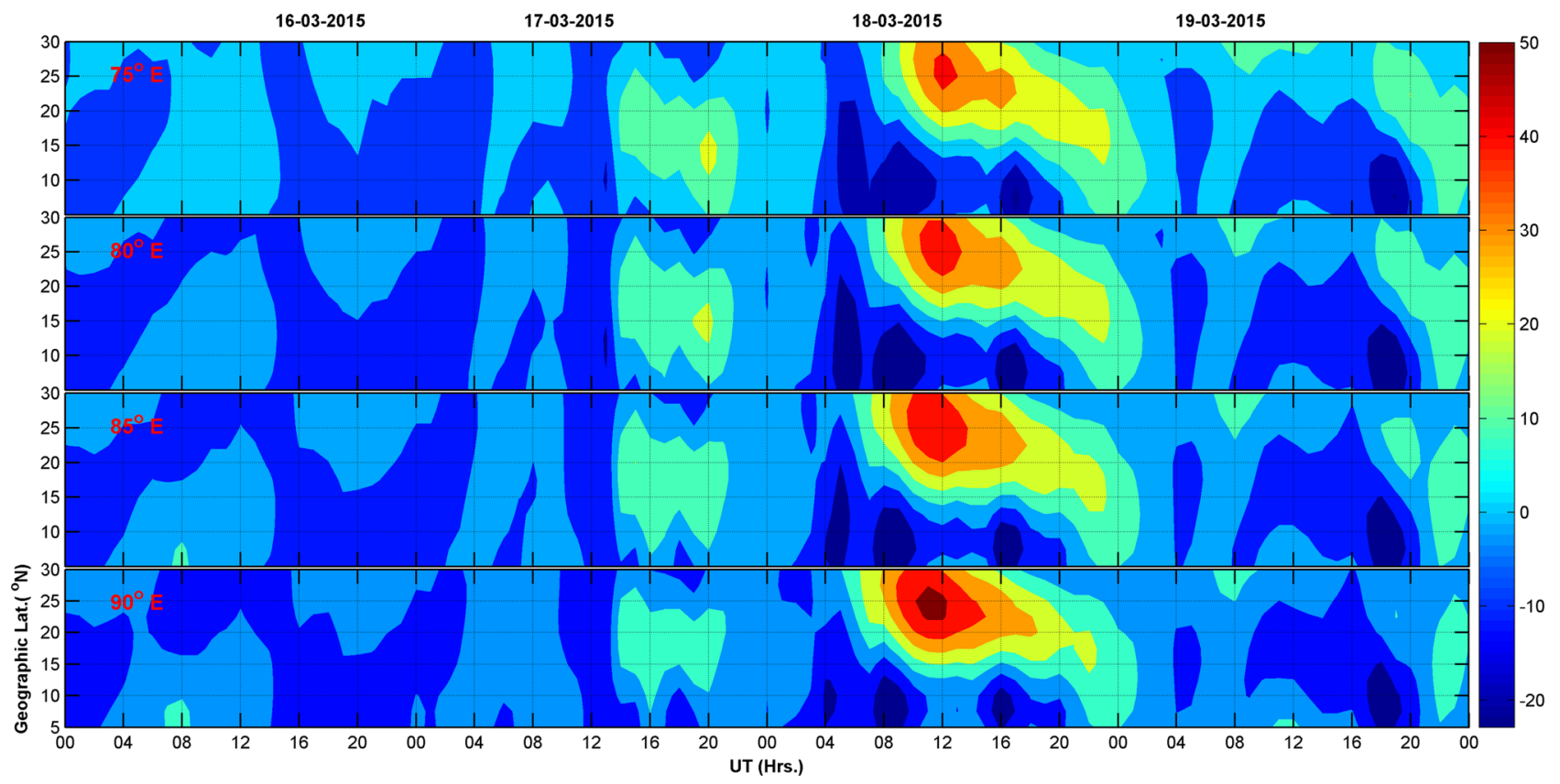

Figure 7. Delta GIM TEC (diffTEC) over $75^{\circ} \mathrm{E}, 80^{\circ} \mathrm{E}, 85^{\circ} \mathrm{E}$ and $90^{\circ} \mathrm{E}$ longitudes during $16-19$ March 2015 .

From figure 5, during the initial phase ( 04:45 to $\sim 07: 00 \mathrm{UT}$ ) on 17 March 2015, the GPS TEC almost coincided with the quiet time mean values over all the stations. Except for LHAZ and LCK4, a positive storm effect during $\sim 07: 00$ to $\sim 12: 30$ UT and negative storm effect during $\sim 12: 30$ UT to till the end of the main phase had been observed over other stations. LHAZ and LCK4 stations lay the outer edge of the northern anomaly over Indian sector. The observed positive storm phase is in agreement with the earlier reports by Astafyeva et al. (2015) and Nava et al. (2016) over the Asian sector, particularly at mid-latitudes. The positive storm effect observed during 07:00 to 12:30 UT (i.e., 12:30 to 18:00 IST) was mainly due to the eastward PPEF-enhanced electric field (FullerRowell et al. 1994, 1996). The negative storm effect after $\sim 12: 30 \mathrm{UT}$ is due to energy inputs 
from $\mathrm{AE}$ index, decrease of $\mathrm{O} / \mathrm{N}_{2}$ (Astafyeva et al. 2015; Nava et al. 2016) and also due to equator ward meridional winds (Ramsingh Sripathi et al. 2015; Kalita et al. 2016). Another important point noted here is that for the HYDE station around 14:00 UT, a large peak was observed. At this time, only five PRNs were contributing the TEC within an assumed cut off. Among these PRNs, one of the PRN contributes very high TEC value about $\sim 127$ TECU and the remaining contributed between $\sim 15$ and 75 TECU. On an average, a large peak was observed. From this case, it is clear that the different lines of sights from satellites to receiver provide different values, which is a somewhat serious concern particularly during the storm period. The positional estimation with the triangulation method will provide large errors in the ranging measurements, and hence, one must be cautious on the line of sight during severe geomagnetic storm conditions.

During the early hours (UT) of 18 March, except for LCK4 and LHAZ, the remaining stations (figure 5) showed positive storm effect with higher TEC values over low-latitude stations. During these hours, from low latitudes to mid-latitudes (SGOC to LHAZ), the positive storm effect diminished and turned into a negative storm effect and the same was also observed in figures 6 and 7 . This confirms that there is a large deposition of electron density near magnetic equator and it was consistent with the results of Ramsingh Sripathi et al. (2015) during this storm over Indian sector. Ramsingh Sripathi et al. (2015) have reported that on 18 March 2015, initially during the morning hours, the EIA initiated to develop due to daytime $\mathrm{E} \times \mathrm{B}$ drifts and strong equatorial electrojet (EEJ) currents, and as time progressed, the EIA weakened due to the development of the counter electrojet (CEJ) currents. Due to this westward DDEF, the development of EIA is reduced and the ionisation is confined near magnetic equator over Indian sector. Sastri (1988) suggested that the westward DDEFs caused the reduction in EEJ during daytime and the consequent effect of inhibition of EIA. During the recovery phase, a large negative storm effect was seen at a mid-latitude station LHAZ, whereas it was moderate at LCK4, which was consistent with the earlier reports by Astafyeva et al. (2015) and Nava et al. (2016).

From figure 6, during the main phase of the storm, latitudinal suppression $\left(30^{\circ}-0^{\circ}\right)$ of TEC was observed around $\sim 13: 00$ UT over Indian longitudes. This may be due to storm-induced perturbations, which are more favoured for recombination rates in addition to the ceasing of solar EUV flux (dusk sector over these longitudes). Maximum TEC was observed over $80^{\circ} \mathrm{E}$ and $85^{\circ} \mathrm{E}$ longitudes. Latitudinal stretching of the EIA was seen during the main phase of the storm over the above said longitudes, which was well correlated with the earlier reports (Ramsingh Sripathi et al. 2015; Venkatesh et al. 2017 observed in Brazilian sector). Another interesting result from figure 6 is that the crest of the northern EIA shifted about $\sim 10^{\circ}$ towards the magnetic equator during 18 March compared to 17 March. A peak of enhanced TEC was observed at 13:00 UT on 17 March over all longitudes, which may be due to an enhanced PRE by the storm-induced eastward PPEF (figure 4). Enhancement in TEC (blue shade) was observed on 17 March unlike 16 March, which was centred at $\sim 06: 00$ and $\sim 12: 00$ UT as shown in figure 7 . The same was also evident in the foF $\mathrm{F}_{2}$ over equatorial and off-equatorial stations over Indian region as reported by Ramsingh Sripathi et al. (2015), and they are mainly due to PPEFs (figure 4). On 17 March, a large negative storm effect (suppression of TEC) was observed during $\sim 3: 00$ to $\sim 22: 00$ UT (between $\sim 5^{\circ} \mathrm{N}$ and $\sim 25^{\circ} \mathrm{N}$ latitudes) over the said longitudes and also exhibited a butterfly-like structure (figure 7).

Large suppression of TEC over EIA was seen over all the said longitudes during the recovery phase, particularly on 18 March (figures 6 and 7 ). Figure 7 shows the peak structure of positive storm effect observed at three time epochs centred on $\sim 05: 00, \sim 09: 00$ and $\sim 17: 00 \mathrm{UT}$, which is also manifested in figure 3 . These observed regions of peak positive storm effect are confined to low latitudes. In other words, the northern crest of EIA tends towards the magnetic equator or diffusion of plasma along field lines. Further, on the same day, the negative storm effect was seen between $\sim 15^{\circ}$ and $\sim 30^{\circ} \mathrm{N}$ latitudes over the said longitudes. The peak of the negative storm effect centred on $\sim 12: 00 \mathrm{UT}$ at $\sim 25^{\circ} \mathrm{N}$ latitude declined towards lower latitudes (Ramsingh Sripathi et al. 2015) with the progression of time. This peak of the negative storm effect was more prominent over $90^{\circ} \mathrm{E}$ longitude. During daytime, the evolution of EIA was mainly controlled by the global scale zonal eastward electric field. This electric field with the horizontal north-south magnetic field will manifest the vertical $\mathrm{E} \times \mathrm{B}$ drifts. These vertical $\mathrm{E} \times \mathrm{B}$ drifts lift the ionosphere plasma to higher altitudes, and also, the plasma diffuses downward 
along the geomagnetic field lines under gravity and pressure gradients. Storm-induced PPEF during dawn-to-dusk sector under southward turning of IMF $\mathrm{Bz}$ conditions is in phase with the global scale zonal eastward electrified. These PPEFs will manifest large enhancements in the upward vertical drifts and lift the plasma to higher altitudes where the recombination rate is very less; consequently, large enhancement of TEC in EIA occurs during the daytime (Huang et al. 1989; Maruyama et al. 2004). DDEFs induced by the equator ward winds (Blanc and Richmond 1980; Fuller-Rowell et al. 1994, 1996) are westward during the daytime. These strong westward DDEFs during the daytime may suppress the EIA generation, which resulted in a large negative storm effect, and may be one of the causes for the occurrence of negative storm on 18 March 2015. Nava et al. (2016) have observed a large negative storm effect during the recovery phase of the storm over Asian sector, particularly at high and mid-latitudes, and reported that this was mainly due to two large energy inputs occurring during the evening and the night side over Asian sector. From the spectral analysis of magnetic field $(H)$, they concluded that the presence of DDEF and their oscillations during the storm lasted for several hours after the SSC. Huang et al. (2016) have reported the disturbance dynamo-induced vertical drifts, compositional changes in the equatorial ionosphere during night side from DMSP satellite data. They concluded that the long lasting dynamo process during the recovery phase may be related to flywheel effect of disturbance neutral winds. During the daytime, the GUVI $\left(\mathrm{O} / \mathrm{N}_{2}\right)$ maps (Astafyeva et al. 2015; Kuai et al. 2016; Nava et al. 2016) showed the confinement of ionisation over latitudes near the magnetic equator over Asian sector during the recovery phase of the storm. The results observed in figures 5 and 6 are consistent with earlier studies observed on this storm (Astafyeva et al. 2015; Huang et al. 2016; Nava et al. 2016).

\subsubsection{Storm time scintillation}

PRE is one of the important drivers for the postsunset uplift of the ionosphere plasma to higher altitudes, which leads to the generation of irregularities in the ionosphere particularly during the dusk sector. Earlier studies (Ramsingh Sripathi et al. 2015; Tulasi Ram et al. 2015; Kakad et al. 2016; Patra et al. 2016) revealed that the Indian sector was more favourable for the generation of intense post-sunset ESF irregularities and EPBs, which was mainly due to the main phase of the storm that falls in dusk sector. Storm time PPEF at dusk sector further enhances the PRE and triggers the post-sunset rise of the plasma to higher altitudes, which leads to the onset of electron density irregularities (Kakad et al. 2016; Kalita et al. 2016; Nayak et al. 2017). During this storm, over Indian longitudes, the eastward PPEF was enhanced by the PRE around 13:00 UT (figure 4), which leads to the uplift of plasma to higher altitudes, and resulted in the consequent generation of EPBs.

Ramsingh Sripathi et al. (2015) and Tulasi Ram et al. (2015) have observed that the h'F over Tirunelveli (equatorial station) was lifted to $\sim 560 \mathrm{~km}$ with a vertical drift of $70 \mathrm{~m} / \mathrm{s}$. Patra et al. (2016) have observed an uplift of the F layer to $470 \mathrm{~km}$ with a peak upward velocity of $50 \mathrm{~m} / \mathrm{s}$ over off-equatorial station, Gadanki, which is a subsequent generation of post-sunset ESF irregularities causing scintillation on GPS L-band signals. Above studies revealed that these intense irregularities and EPBs extended from $27.13^{\circ} \mathrm{N}$ to $25.98^{\circ} \mathrm{S}$ magnetic dip latitudes and longitudinally in a narrow zone between $69^{\circ} \mathrm{E}$ and $98^{\circ} \mathrm{E}$ over Indian sector. In this section, we made an attempt to estimate how much these irregularities caused the scintillation on L-band signals of GPS, GLONASS constellations over WALT. The scintillation observations with an elevation $>30^{\circ}$ were considered for avoiding the site-specific multipath effect. The amplitude scintillations (S4) and phase scintillations $\left(\sigma_{\varphi}\right)$ on L1 signal of GPS and L1-band and L2-band signals of GLONASS are presented in the following sections.

\subsubsection{L-band scintillation of GPS and GLONASS constellations}

Figure 8 shows scintillations on GPS L1 (1575 $\mathrm{MHz}$ ) signal over WALT. The colours green, red and black represent the phase scintillation index (phase sigma $\sigma_{\varphi}$ ), amplitude scintillation index (S4) and TEC, respectively. For GPS L1 signal, almost 12 PRNs (90\% of visible PRNs) show phase and amplitude scintillation during 13:30 to 19:30 UT (19:00 to 25:00 IST). Except for PRN numbers 5 and 12, the remaining 10 PRNs show strong amplitude scintillation (84\%) and their corresponding peak $\mathrm{S} 4$ index ranges from 0.36 to 0.74. In except few cases, the occurrence of phase scintillations was correlated with amplitude 
PRN:1 S4: 0.61 Ph.Si.: 0.44
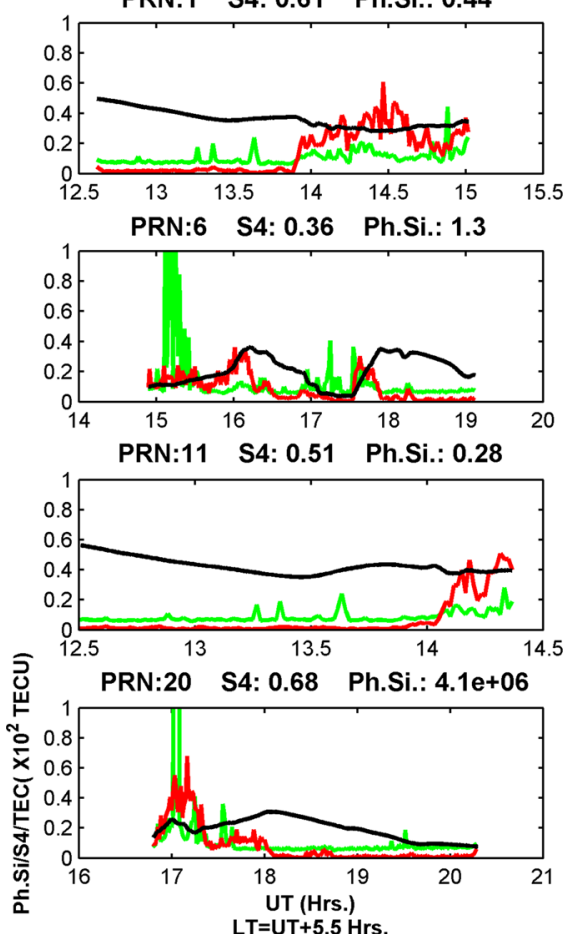

PRN:2 S4: 0.65 Ph.Si.: 0.53
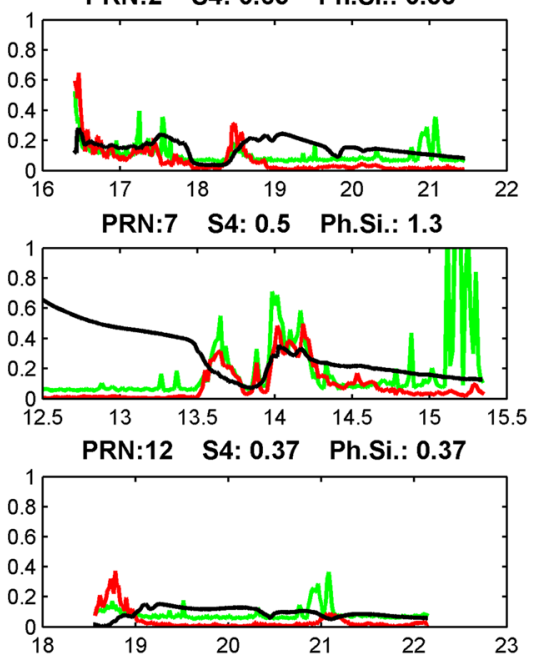

PRN:28 S4: 0.71 Ph.Si.: 5.9e+06

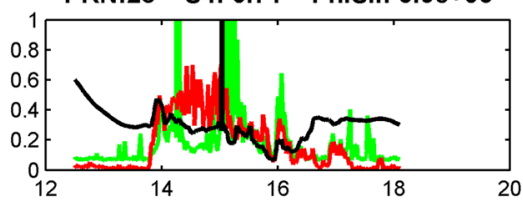

PRN:5 S4: 0.11 Ph.Si.: 0.36
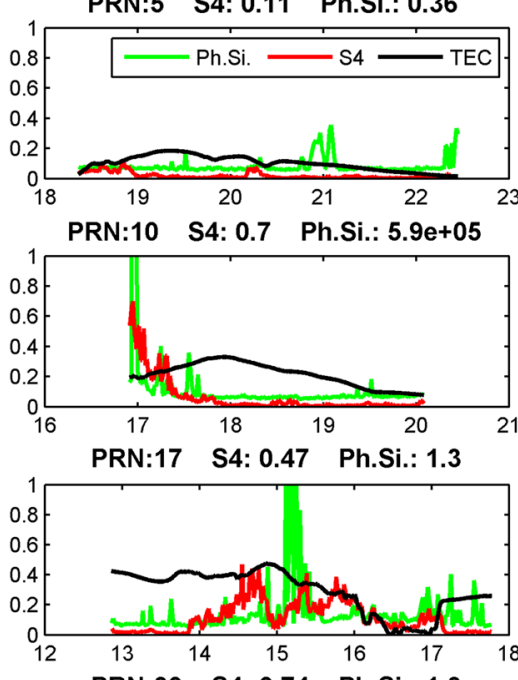

PRN:30 S4: 0.74 Ph.Si.: 1.3

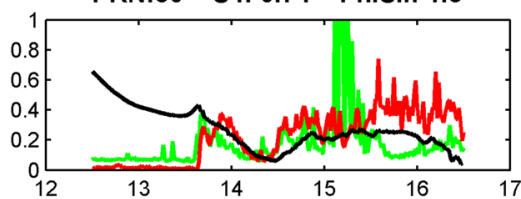

Figure 8. GPS L1 frequency (1575 MHz) scintillations over WALT during 17 March 2015. The colours represent, red: amplitude scintillation index (S4), green: phase scintillation index $\left(\sigma_{\varphi}\right)$ and black: TEC.

scintillations. The PRNs 10, 20 and 28 show large phase deviations (phase slips). In most of the cases, wavy structure was seen in TEC. The trough of the wave structure indicates the depth of the drifting cross-section of a drifting EPB.

Figures 9 and 10 represent scintillations on GLONASS L1-band (1238-1254 MHz) and L2band (1593-1609 MHz) signals over WALT. L2band signals show higher scintillation indices than L1-band signals, which is due to the frequency dependence of scintillation. L2-band shows higher number of phase slips than L1-band for the same satellite PRN. Very few of them on L2-band coincide with the phase deviations of same PRN transmitting on the L1-band and have higher values of phase scintillation indices instead of phase slips on L1-band. The satellite PRNs 10, 14 and 20 show weak phase scintillation on both the signal bands, but there are no considerable amplitude scintillations. The peak S4 index for GLONASS ranges from 0.16 to 0.70 and 0.18 to 0.94 , respectively, for L1 and L2-band signals.

The enhanced scintillation activity observed on 17 March compared to quiet days during the postsunset period is mainly due to PPEFs (figure 4) and their consequent effect on vertical drifts of the plasma in the ionosphere. From figures 7 to 10 , it is clear that $12 \mathrm{PRNs}$ of GPS and nine PRNs of GLONASS show phase/amplitude scintillation on the carrier signals of L1, L1-band, and L2-bands of their respective constellation. Most of them are strong scintillation, and almost all the visible satellites over a site were affected by scintillation. The temporal and spatial coverage of GPS over a station is better than that of GLONASS (Srinivasu et al. 2017). Because of this specific reason, higher number of PRNs of GPS was affected by scintillation. It is clear that most of the assumed space, L-band signals, severely suffered by strong scintillation, which is a serious threat to satellite navigation/aviation systems particularly during severe storm periods. The degree of severity leads to the loss of information on these carrier signals. If it is more severe, then it further leads to a communication failure between the satellite and the user receiver. In such severe cases, combined observations from various constellations will give a better estimation of scintillation, because within a same common volume over a station, each satellite of the respective constellation will make a different line of sight with the receiver and hence covers larger space.

In addition to amplitude and phase scintillation over WALT, further, we analysed the scintillation 
PRN:9 S4 :0.16 Ph. Si. :0.39

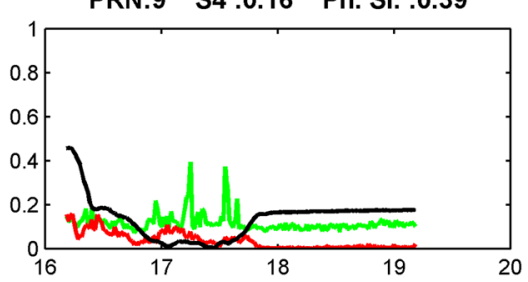

PRN:15 S4:0.7 Ph. Si. :1.3
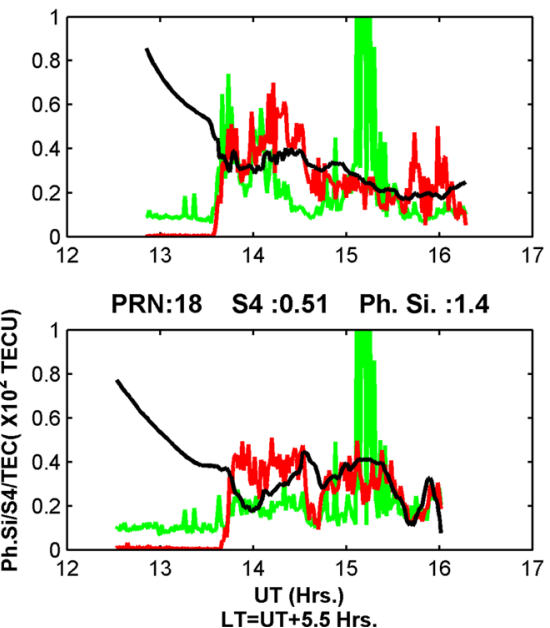

PRN:10 S4 :0.035 Ph. Si. :0.18

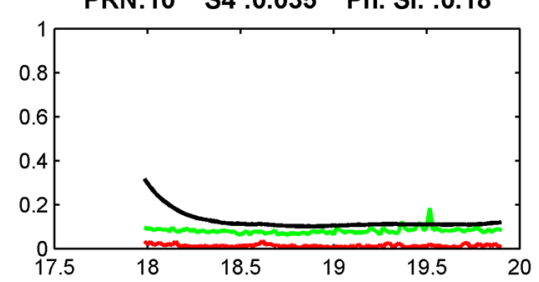

PRN:16 S4:0.66 Ph. Si. :1.4
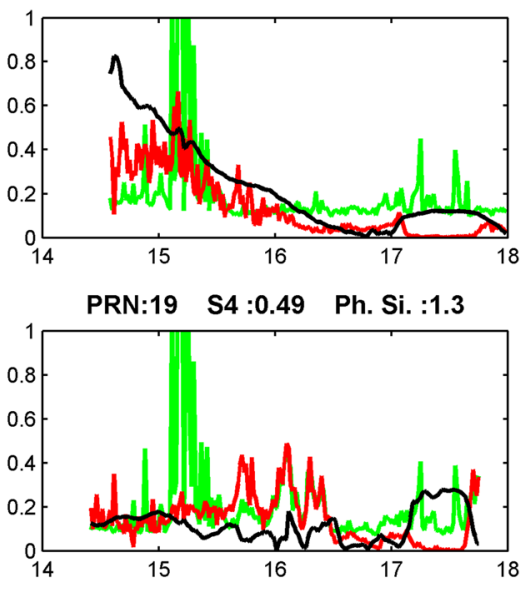

PRN:14 S4 :0.088 Ph. Si : 0.27

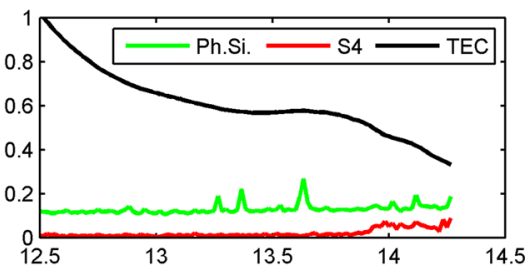

PRN:17 S4:0.55 Ph. Si. :0.84
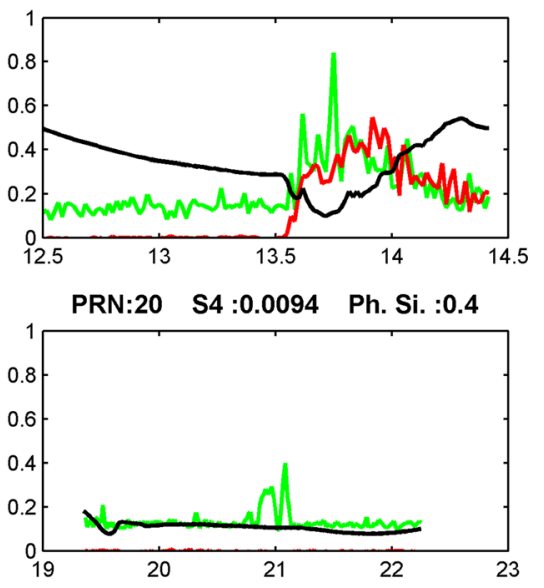

Figure 9. GLONASS scintillation L1-band (1593-1609 MHz) over WALT during 17 March 2015. The colours represent, red: amplitude scintillation index (S4), green: phase scintillation index $\left(\sigma_{\varphi}\right)$ and black: TEC.
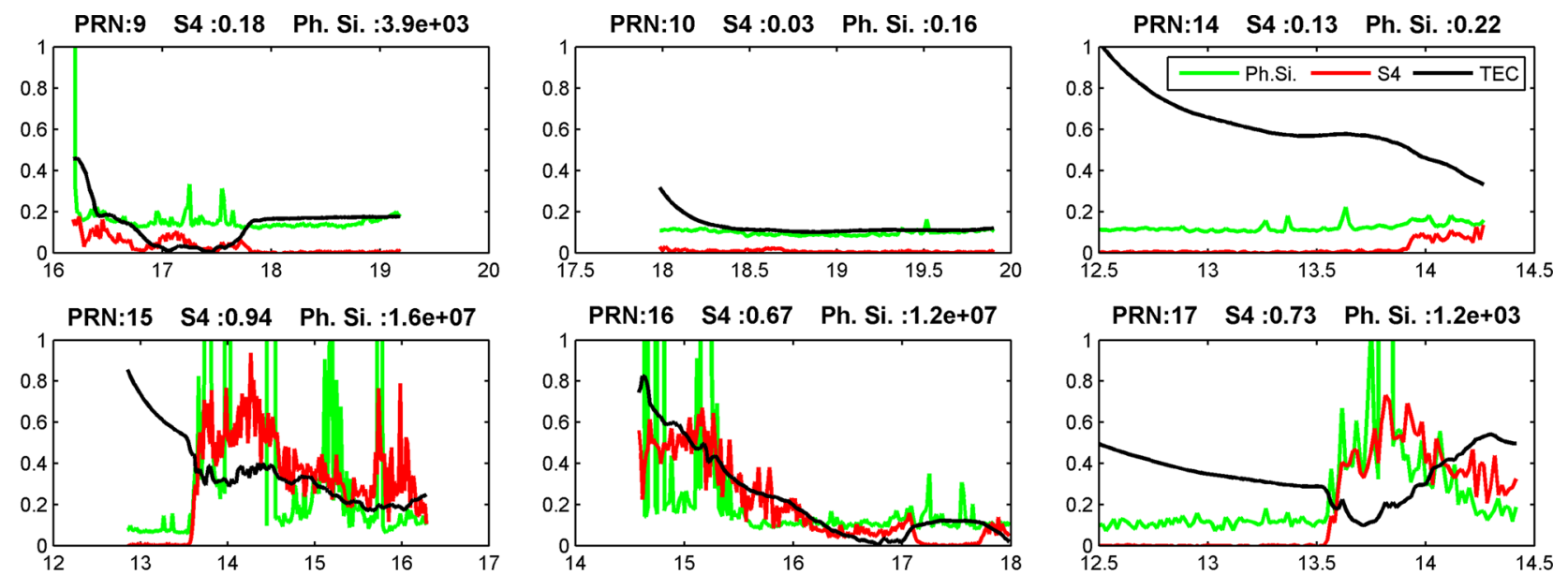

PRN:16 S4:0.67 Ph. Si. :1.2e+07

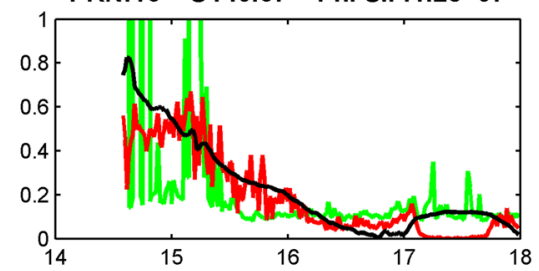

PRN:17 S4 :0.73 Ph. Si. : 1.2e+03
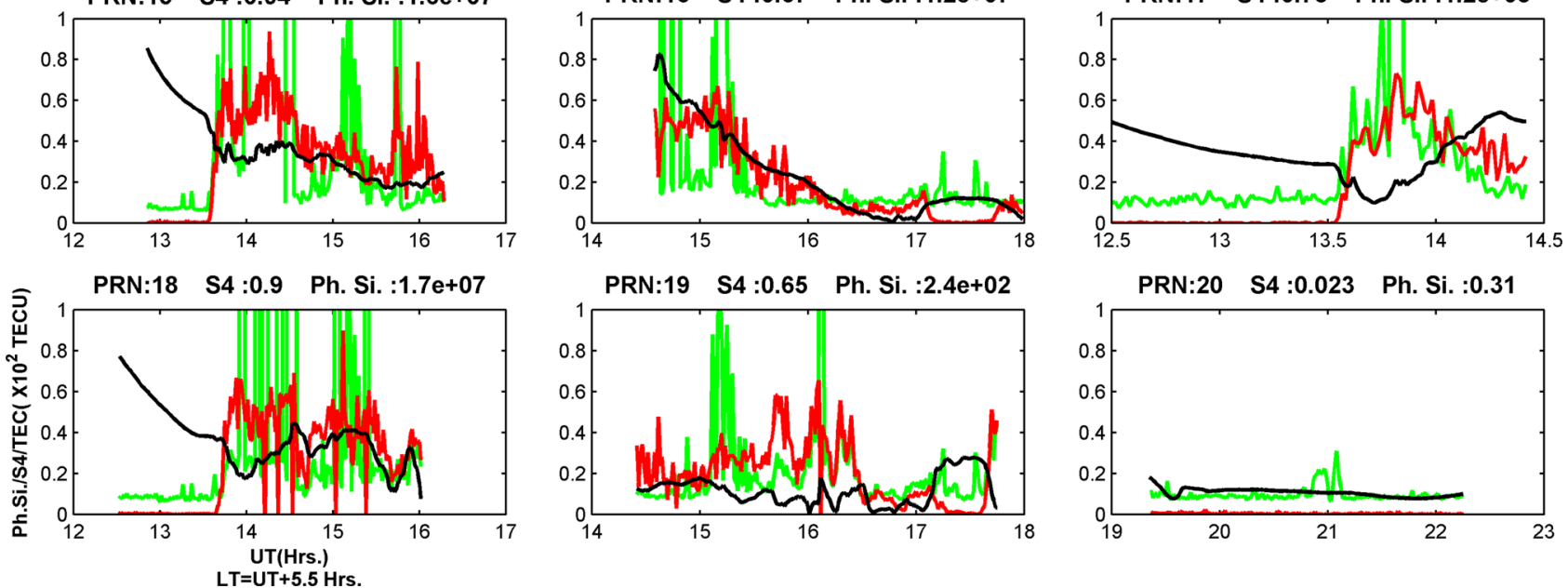

Figure 10. GLONASS scintillation L2-band (1238-1254 MHz) over WALT during 17 March 2015. The colours represent, red: amplitude scintillation index (S4), green: phase scintillation index $\left(\sigma_{\varphi}\right)$ and black: TEC. 

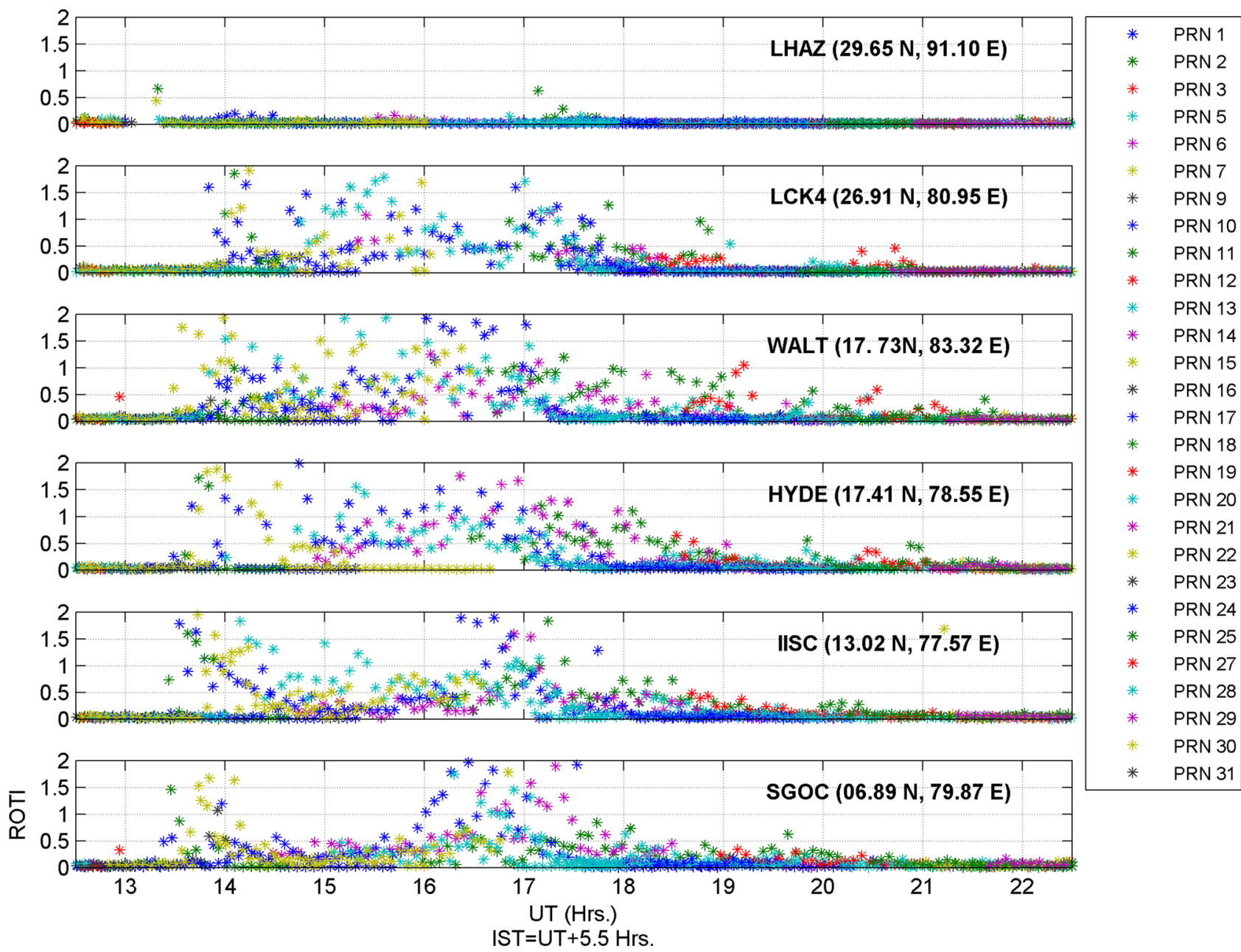

Figure 11. Variation of rate of TEC index (ROTI) over the stations LAHZ, LCK4, HYDE, WALT, VADD, IISC and SGOC.

signatures on TEC in terms of ROTI of each satellite PRN over six stations. For each station, the ROTI index of each PRN is presented with a colour code, as shown in figure 11, during 12:30 to 22:30 UT (18:00 to 04:00 IST) on 17 March 2015. The panels of figure 11 from top to bottom represent the stations LHAZ, LCK4, WALT, HYDE, IISC and SGOC, respectively. Except for LHAZ, all stations show strong fluctuations in ROTI during 13:30 to 21:30 UT (19:00 to 03:00 IST), which is consistent with the previous studies over Indian region (Ramsingh Sripathi et al. 2015; Tulasi Ram et al. 2015; Kakad et al. 2016; Patra et al. 2016; Nayak et al. 2017; Sau et al. 2017). LHAZ lies around $90^{\circ} \mathrm{E}$ longitude also beyond the northern EIA region, and this may be one of the reasons for the absence of fluctuations in ROTI. During the post-sunset hours, the magnitude of ROTI has higher values, whereas during post-midnight hours, the magnitude drastically diminishes. The ROTI over WALT was well correlated with the amplitude and phase scintillation particularly during
13:30 to 18:30 UT (19:00 to 0000 IST). Patra et al. (2016) have observed considerable irregularities during post-midnight hours of GIRI (30 $\mathrm{MHz}$ ) observations over Gadanki. We also observed weak scintillations on the L-band signals with small durations and also in ROTI during post-midnight hours over the said stations.

\section{Conclusions}

The response of ionospheric TEC, scintillations (amplitude and phase) from GPS and GLONASS constellations, and ROTI during the St. Patrick's Day storm of 17 March 2015 has been investigated. The important results are summarised as follows:

- The variation of diffTEC over WALT from two different constellations GPS, GLONASS and GIM CODE TEC has been compared. Most of the time, the GLONASS-derived diffTEC follows the same trend but have higher values 
( $\sim 4$ TECU) than that of GPS, which may be due to different frequency set of each satellite of GLONASS for calculating TEC. The diffTEC derived from CODE GIM TEC is underestimated and anti-correlated with GPS and GLONASS mainly during the recovery phase of the storm on 19 March, which may be due to limited availability of data sets over the Indian sector to the input of the model to derive the CODE GIM TEC data.

- The positive and negative storms observed at WALT during the main and recovery phases of the storm in diffTEC and CODE GIM TEC maps are well correlated with the previous studies on this storm by Ramsingh Sripathi et al. (2015). The daytime positive storm effect during the main phase of the storm is mainly due to PPEF and negative storm effect during recovery phase is due to DDEFs.

- On 18 March 2015, large deposition of TEC near magnetic equator was observed in Indian longitudes in CODE GIM TEC maps. Three positive storm peaks were also observed. These peaks are also implicated in GPS and GLONASS TEC over Indian sector. This is mainly due to the influence of DDEFs on the daytime eastward electric field (Ramsingh Sripathi et al. 2015). The large negative storm effect was observed over LHAZ and LCK4 on 18 March.

- Strong amplitude and phase scintillations were observed over WALT in L-band signals of GPS and GLONASS constellations. Twelve satellite PRNs of GPS L1 and nine PRNs of GLONASS L1 and L2-band signals were affected by amplitude and phase scintillations. The peak amplitude scintillation index (S4) obtained from the effected PRNs ranges from 0.36 to 0.74 for GPS L1 signal and 0.36 to 0.76 for GLONASS L1band signals. The fluctuations in TEC in terms of ROTI are also observed on 17 March 2015. The results suggest that the scintillation activity during this storm over Indian longitudes was enhanced due to the main phase of the storm falls on dusk-to-dawn sector and its consequent enhancement of the PRE.

\section{Acknowledgements}

Authors wish to express their sincere thanks to ISRO for providing GPStation-6 under SSPS program. One of the authors (VKDS) wishes to express his sincere thanks to UGC for providing UGC-BSR Senior Research Fellowship. Authors wish to express their sincere thanks to IGS network (ftp://cddis.gsfc.nasa.gov/pub/gps/products /ionex) for providing the GIM and GPS TEC datasets. Thanks are due to OMNI web interface for providing solar wind parameters (https://omniweb. gsfc.nasa.gov/form/omni_min.html). Authors also acknowledge the web page (http://geomag.org/ models/PPEFM/RealtimeEF.html) for model-derived PPEF datasets. The authors are thankful to World Data Centre for Geomagnetism, Kyoto, for providing the quiet day information (http://wdc.ku gi.kyoto-u.ac.jp/qddays/index.html).

\section{References}

Abdu M A 1997 Major phenomena of the equatorial ionosphere thermosphere system under disturbed conditions; J. Atmos. Sol. Terr. Phys. 59 1505-1519, https://doi.org/ 10.1016/S13646826(96)00152-6.

Astafyeva E, Zakharenkova I and Forster M 2015 Ionospheric response to the 2015 St. Patrick's day storm: A global multi-instrumental overview; J. Geophys. Res. 1209023 9037, https://doi.org/10.1002/2015JA02162.

Blanc M and Richmond A D 1980 The ionospheric disturbance dynamo; J. Geophys. Res. 85 1669-1686, https:// doi.org/10.1029/JA085iA04p01669.

Borries C, Mahrous A M, Ellahouny N M and Badeke R 2016 Multiple ionospheric perturbations during the Saint Patrick's Day storm 2015 in the European-African sector; J. Geophys. Res. 121 11,333-11,345, https://doi.org/10. 1002/2016JA023178.

Carter B A, Yizengaw E, Pradipta R, Retterer J M, Groves K, Valladares C, Caton R, Bridgwood C, Norman R and Zhang K 2016 Global equatorial plasma bubble occurrence during the 2015 St. Patrick's day storm; J. Geophys. Res. 121 894-905, https://doi.org/10.1002/2015JA02219.

Danilov A 2013 Ionospheric F region response to geomagnetic disturbances; Adv. Space Res. 52(3) 343-366, https://doi.org/10.1016/j.asr.2013.04.019.

Fagundes P R, Cardoso F A, Fejer B G, Venkatesh K, Ribeiro B A G and Pillat V G 2016 Positive and negative GPSTEC ionospheric storm effects during the extreme space weather event of March 2015 over the Brazilian sector; J. Geophys. Res. 121 5613-5625, https://doi.org/10. 1002/2015JA022214.

Fejer B G, Scherliess L and de Paula E R 1999 Effects of the vertical plasma drift velocity on the generation and evolution of equatorial spread F; J. Geophys. Res. 104 19,859-19,869, https://doi.org/10.1029/1999JA900271.

Fejer B G, Jensen J W and Su S Y 2008 Seasonal and longitudinal dependence of equatorial disturbance vertical plasma drifts; Geophys. Res. Lett. 35 L20106. https:// doi.org/10.1029/2008GL035584.

Forster M and Jakowski N 2000 Geomagnetic storm effects on the topside ionosphere and plasmasphere: A compact 
tutorial and new results; Surv. Geophys. 21(1) 47-87, https://doi.org/10.1023/A:1006775125220.

Fuller-Rowell T J, Codrescu M V, Moffett R J and Quegan S 1994 Response of the thermosphere and ionosphere to geomagnetic storms; J. Geophys. Res. 99 3893-3914, https://doi.org/10.1029/93JA02015.

Fuller-Rowell T J, Codrescu M V, Rishbeth H, Moffett R J and Quegan S 1996 On the seasonal response of the thermosphere and ionosphere to geomagnetic storms; J. Geophys. Res. 101 2343-2353, https://doi.org/10. 1029/95JA01614.

Gonzalez W D, Joselyn J A, Kamide Y, Kroehl H W, Rostoker G, Tsurutani B T and Vasyliunas V M 1994 What is a geomagnetic storm? J. Geophys. Res. 99(A4) 57715792. https://doi.org/10.1029/93JA02867.

GPStation-6TM 2012 GNSS ionospheric scintillation and TEC monitor (GISTM) receiver; User manual, OM20000132, Rev 2, November 2012, NovAtel Inc., Calgary, Canada.

Huang C S 2009 Eastward electric field enhancement and geomagnetic positive bay in the dayside low-latitude ionosphere caused by magnetosphericsubstorms during sawtooth events; Geophys. Res. Lett. 36 L18102, https:// doi.org/10.1029/2009GL040287.

Huang C S 2012 Statistical analysis of dayside equatorial ionospheric electric fields and electrojet currents produced by magnetosphericsubstorms during sawtooth events; J. Geophys. Res. 117 A02316, https://doi.org/10. 1029/2011JA017398.

Huang C Y, Burke W J, Machuzak J S, Gentile L C and Sultan P J 2001 DMSP observations of equatorial plasma bubbles in the topside ionosophere near solar maximum; J. Geophys. Res. 106 8131-8142, https://doi.org/ 10.1029/2000JA000319.

Huang Y, Cheng K and Chen S 1989 On the equatorial anomaly of the ionospheric total electron content near the northern anomaly crest region. J. Geophys. Res. 94(A10) $13,515-13,525$.

Huang C S, Wilson G R, Hairston M R, Zhang W W and Liu J 2016 Equatorial ionospheric plasma drifts and $\mathrm{O}+$ concentration enhancements associated with disturbance dynamo during the 2015 St. Patrick's Day magnetic storm; J. Geophys. Res. 121 7961-7973, https://doi.org/ 10.1002/2016JA023072.

Kakad B, Gurram P, Tripura Sundari P N B and Bhattacharyya A 2016 Structuring of intermediate scale equatorial spread $\mathrm{F}$ irregularities during intense geomagnetic storm of solar cycle 24; J. Geophys. Res. 121 7001-7012, https://doi.org/10.1002/2016JA022635.

Kalita B R, Hazarika R, Kakoti G, Bhuyan P K, Chakrabarty D, Seemala G K, Wang K, Sharma S, Yokoyama T, Supnithi P, Komolmis T, Yatini C Y, Le Huy M and Roy P 2016 Conjugate hemisphere ionospheric response to the St. Patrick's Day storms of 2013 and 2015 in the $100^{\circ} \mathrm{E}$ longitude sector; J. Geophys. Res. 121 11,364-11,390, https://doi.org/10.1002/2016JA023119.

Kamide Y and Kusano K 2015 No major solar flares but the largest geomagnetic storm in the present solar cycle; Space Weather 13 365-367, https://doi.org/10. 1002/2015SW001213.

Kikuchi T, Luhr H, Kitamura T, Saka O and Schlegel K 1996 Direct penetration of the polar electric fields to the equator during a DP2 event as detected by the auroral and equatorial magnetometer chains and the EISCAT radar; J. Geophys. Res. 101 17,161-17,173.

Kikuchi T, Luhr H, Schlegel K, Tachihara H, Shinohara M and Kitamura T L 2000 Penetration of auroral electric fields to the equator during a substorm; J. Geophys. Res. 105 23,251-23,252, https://doi.org/10.1029/ 2000JA900016.

Kuai J, Liu L, Liu J, Sripathi S, Zhao B, Chen Y, Le H and $\mathrm{Hu} \mathrm{L} 2016$ Effects of disturbed electric fields in the low latitude and equatorial ionosphere during the 2015 St. Patrick's Day storm; J. Geophys. Res. 121 9111-9126, https://doi.org/10.1002/2016JA022832.

Loewe C A and Prölss G W 1997 Classification and mean behavior of magnetic storms; J. Geophys. Res. 102 14,209-14,213, https://doi.org/10.1029/96JA04020.

Manoj C and Maus S 2012 A real-time forecast service for the ionospheric equatorial zonal electric field; Space Weather 10, https://doi.org/10.1029/2012SW00082.

Maruyama T, Ma G and Nakamura M 2004 Signature of TEC storm on 6 November 2001 derived from dense GPS receiver network and ionosonde chain over Japan; J. Geophys. Res. 109 A10302, https://doi.org/10.1029/ 2004JA010451.

Nava B, Rodríguez-Zuluaga J, Alazo-Cuartas K, Kashcheyev A, Migoya-Orué Y, Radicella S, Amory-Mazaudier C and Fleury R 2016 Middle- and low-latitude ionosphere response to 2015 St. Patrick's day geomagnetic storm; J. Geophys. Res. 121 3421-3438, https://doi.org/10. 1002/2015JA02229.

Nayak C, Tsai L C, Su S Y, Galkin I A, Caton R G and Groves K M 2017 Suppression of ionospheric scintillation during St. Patrick's Day geomagnetic super storm as observed over the anomaly crest region station Pingtung, Taiwan: A case study; Adv. Space Res. 60 396-405, https://doi.org/10.1016/j.asr.2016.11.036.

Nishida A 1968 Geomagnetic DP 2 fluctuations and associated magnetospheric phenomena; J. Geophys. Res. 73 1795-1803, https://doi.org/10.1029/JA073i005p01795.

Patra A K, Chaitanya P P, Dashora N, Sivakandan M and Taori A 2016 Highly localized unique electrodynamics and plasma irregularities linked with the 17 March 2015 severe magnetic storm observed using multitechnique common-volume observations from Gadanki, India; J. Geophys. Res. 121 11,518-11,527, https://doi.org/10. 1002/2016JA023384.

Pi X, Mannucci A J, Lindqwister U J and Ho C M 1997 Monitoring of global ionospheric irregularities using the worldwide GPS network; Geophys. Res. Lett. 24 2283, https://doi.org/10.1029/97GL02273.

Prölss G W 1995 Ionospheric F region storms; In: Handbook of atmospheric electrodynamics (ed.) Volland H, Vol. 2, CRC Press, Boca Raton, London, pp. 195-248.

Rama Rao P V S, Niranjan K, Prasad D S V V D, Gopi Krishna S and Uma G 2006 On the validity of the ionospheric pierce point (IPP) altitude of $350 \mathrm{~km}$ in the Indian equatorial and low-latitude sector; Ann. Geophys. 24 2159-2168, https://doi.org/10.5194/angeo-24-2159-2006.

Ramsingh Sripathi S, Sreekumar S, Banola S, Emperumal K, Tiwari P and Kumar B S 2015 Low-latitude ionosphere response to super geomagnetic storm of 17/18 March 2015: Results from a chain of ground-based observations 
over Indian sector; J. Geophys. Res., https://doi.org/10. 1002/2015JA021509.

Richmond A D, Peymirat C and Roble R G 2003 Longlasting disturbances in the equatorial ionospheric electric field simulated with a coupled magnetosphere-ionosphere thermosphere model; J. Geophys. Res. 108(A3) 1118, https://doi.org/10.1029/2002JA009758.

Rishbeth H 1991 F-region storms and thermospheric dynamics; J. Geomagn. Geoelectr. 43 513-524, https://doi.org/ 10.5636/jgg.43.Supplement1_513.

Sastri J H 1988 Equatorial electric-fields of ionospheric disturbance dynamo origin; Ann. Geophys. 6(6) 635642 .

Sastri J H, Sridharan R and Kumar Pant T 2003 Equatorial ionosphere-thermosphere system during geomagnetic storms; In: Disturbances in geospace: The storm-substorm relationship (eds) Sharma A S, Kamide Y and Lakhina G S, AGU, Washington, D.C., pp. 185-203, https://doi.org/ 10.1029/142GM16.

Sau S, Narayanan V L, Gurubaran S, Ghodpage R N and Patil P T 2017 First observation of inter hemispheric asymmetry in the EPBs during the St.Patrick's Day geomagnetic storm of 2015; J. Geophys. Res. 122, https:// doi.org/10.1002/2017JA024213.

Scherliess L and Fejer B 1997 Storm time dependence of equatorial disturbance dynamo zonal electric fields; J. Geophys. Res. 102 24,037-24,046, https://doi.org/10. 1029/97JA02165.

Seemala G K and Valladares C E 2011 Statistics of total electron content depletions observed over the South American continent for the year 2008; Radio Sci. 46 RS5019, https://doi.org/10.1029/2011RS004722.

Srinivasu V K D, Dashora N, Prasad D S V V D, Niranjan K and Gopi Krishna S 2017 On the occurrence and strength of multi-frequency multi-GNSS ionospheric scintillation in Indian sector during declining phase of solar cycle 24; Adv. Space Res., https://doi.org/10.1016/j.asr.2017.08.036.

Tulasi Ram S, Rama Rao P V S, Prasad D S V V D, Niranjan K, Gopi Krishna S, Sridharan R and Ravindran S 2008 Local time dependent response of postsunset ESF during geomagnetic storms; J. Geophys. Res. 113 A07310, https://doi.org/10.1029/2007JA012922.

Tulasi Ram S, Yokoyama T, Otsuka Y, Shiokawa K, Sripathi S, Veenadhari B, Heelis R, Ajith K K, Gowtam V S, Gurubaran S, Supnithi P and Huy M L 2015 Duskside enhancement of equatorial zonal electric field response to convection electric fields during the St. Patrick's day storm on 17 March 2015; J. Geophys. Res., https://doi. org/10.1002/2015JA021932.

Venkatesh K, Tulasi Ram S, Fagundes P R, Seemala G K and Batista I S 2017 Electrodynamic disturbances in the Brazilian equatorial and low-latitude ionosphere on St. Patrick's Day storm of 17 March 2015; J. Geophys. Res. 122 4553-4570, https://doi.org/10.1002/2017JA024009.

Yeh K C and Lui C H 1982 Radio wave scintillations in the ionosphere; Proc. IEEE 70(4) 324-360.

Zakharenkova I, Astafyeva E and Cherniak I 2016 GPS and GLONASS observations of large-scale traveling ionospheric disturbances during the 2015 St Patrick's Day storm; J. Geophys. Res. 121 12,138-12,156. 